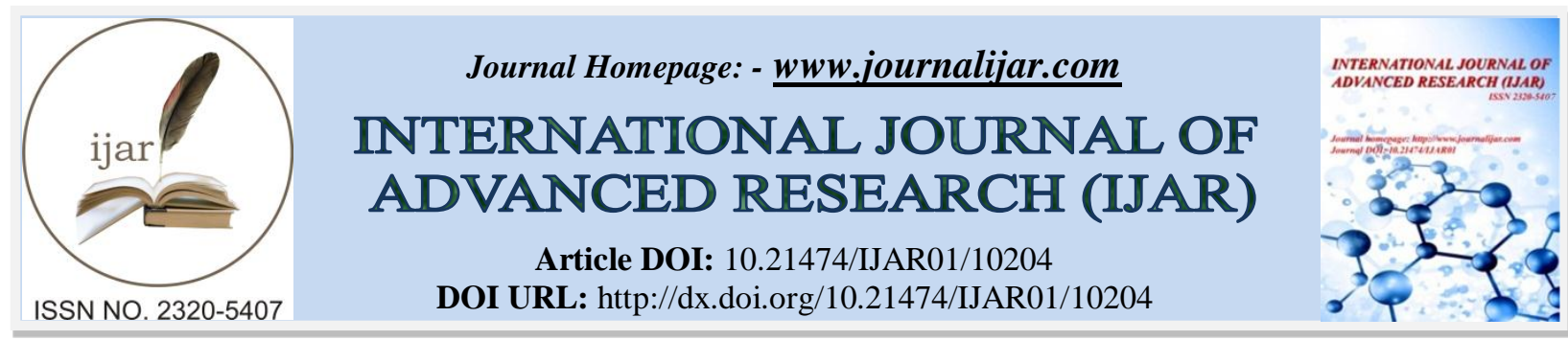

RESEARCH ARTICLE

\title{
SHORT - TERM OUTCOME OF LAPAROSCOPIC APPENDECTOMY VERSUS OPEN APPENDECTOMY IN FEMALES IN CHILD - BEARING PERIOD
}

\author{
Ahmed M. Sallam, Fady Mehaney Habib and Loay M. Gertallah \\ Department of General Surgery, Faculty of Medicine, Zagazig University, Zagazig Egypt.
}

\section{Manuscript Info}

\section{Manuscript History}

Received: 10 October 2019

Final Accepted: 12 November 2019

Published: December 2019

Key words:-

Appendectomy, Laparoscopic, Open, Outcome

\section{Abstract}

This study was conducted to evaluate the results of the laparoscopic versus open appendectomy in females in childbearing period regarding operative time, operative findings, post-operative complications, hospital stay, postoperative analgesia as well as return of the patients to their normal activity. Aim of this study was to detect the suitability and benefit of either laparoscopic appendectomy or open appendectomy to decrease postoperative complications and improves postoperative results especially tubal adhesions in married females.

Methods: This is a prospective randomized comparative study including married female patients from age 18-45 years suffering from acute appendicitis who presented to the Emergency Unit of Surgery Department of Zagazig University during the period from April 2015 to March 2018. These patients were randomly divided into two groups with each had its management approach, open appendectomy group: 27 patients and laparoscopic appendectomy group: 27 patients. The procedure was explained to the patients, and they were consented as regard to the postoperative follow up.

Results: There was statistically significant difference between both groups as regards operative time, post-operative complications, hospital stay, postoperative analgesia as well as return of the patients to their normal activity ( $\mathrm{P}$ value $<0.05)$. On the other hand, there was no statistical difference between the two groups as regard symptoms and signs according to modified Alvarado Score $(P=0.783)$, laboratory findings $(P=0.776)$, preoperative pelvi-abdominal $\mathrm{U} / \mathrm{S}(\mathrm{P}=0.783)$, intra-operative findings $(\mathrm{P}=$ 0.843).

Conclusion: laparoscopic appendectomy is considered a feasible and a safe method in acute appendicitis management and it is still better than open procedure, as it has a shorter duration of hospital stay, a less incidence of wound infection, the need for post- operative analgesia is less than open procedure and a faster patient's return to their daily activities.

Copy Right, IJAR, 2019,. All rights reserved.

Corresponding Author:-Ahmed M. Sallam

Address:-Department of General Surgery, Faculty of Medicine, Zagazig University, Zagazig Egypt. 


\section{Introduction:-}

Appendectomy is considered one of the commonest performed general surgical procedures. In year 1894, Mc-Burney has described the performance of operative appendectomy (OA) for pain located in the right iliac fossa through using gridiron incision. Such procedure has remained the technique of choice for performing appendectomy and has not changed until almost a century later, after Semm has described the Laparoscopic appendectomy (LA) in $1983^{(\mathbf{1})}$.

OA is now considered a safe and effective operation for management of acute appendicitis with less morbidity. But, differences in the inflammatory response and the appendix site which causes operative and post-operative complications. Additionally, OA has been associated with some disadvantages such as; post-operative pain, wound infection and intestinal obstruction that could delay recovery. With recently, LA has emerged as a perfect procedure for both diagnosis and management of acute appendicitis ${ }^{(2)}$.

Numerous studies have showed better clinical patients outcome for LA than $\mathrm{OA}^{(3)}$, while other studies have failed to detect a any advantage ${ }^{(4)}$. With this background, the current study compared the outcomes of LA with OA in married women during their child-bearing period from age 18-45 years old, prospectively as regards to; time of the operation, postoperative pain, duration of staying at hospital, time to continue normal daily activities, in addition to postoperative complications.

\section{Patients and Methods:-}

From April 2015 to March 2018, 54 married females from age 18-45 years with final diagnosis of acute appendicitis were prepared to undergo either OA (group I) or LA (group II), at the Emergency Unit of Surgery Department of Zagazig University.

Inclusion criteria were: 1) Married female aged 18-45 years with acute appendicitis; 2) Patients consented to be included in this study; 3) Non-complicated acute appendicitis.

Exclusion criteria were: 1) current pregnancy; 2) Age $<18>45$ years old; 3) Male patients; 4) Non-married females ; 5) Patients who are treated conservatively ; 6) Patients with complications as appendicular mass, perforation and abscess formation or unfit for surgery.

The study was reviewed and approved by the review board of our faculty and a written consent was taken from all included patients.

All patients preoperatively were investigated by complete blood count (CBC), liver and kidney functions, coagulation profile (PT,PTT,INR), hepatitis viral markers. Pelvi-abdominal ultrasound as radiological investigation.

According to the General Surgery department protocol, all included patients have received; Cefotaxime sodium 1gm and Metronidazole 500mg as a single intravenous single preoperative dose in addition to two postoperative doses.

All included patients in this study were informed about the study nature and the possibility of conversion of LA to OA in the laparoscopic group. We excluded; patients who refused the LA, patients with uncertain diagnosis, patients with palpable abdominal lumps and patients with Alvarado score less than 6 at time of hospital admission.

In case of LA group, they were informed about doing tubal patency evaluation intra-operatively to exclude any previous tubal adhesions and in OA group, they were informed about doing hystrosalpingography (HSG) 1 day post-operative to exclude any previous tubal adhesions.

\section{Surgical procedure:}

The surgeries in the OA patients were done through a McBurney's muscle-splitting incision. The surgeries in the LA patients were done through the three port technique that was performed through $10 \mathrm{~mm}$ (umbilical and left iliac fossa) and one $5 \mathrm{~mm}$ (supra-pubic) ports. The removed appendices were sent for pathologic assessment. 


\section{Follow up:}

Clinical evaluation of all patients and any complications, minor and major, were registered as pain, wound infection, ileus, chest infection and DVT. Postoperative HSG was done after one day in case of open appendectomy group and after three month for both groups to detect any tubal adhesions. The comparison between the 2 groups was in the following criteria; operative time (from skin incision to wound closure), intraoperative findings intraoperative complications, associated pathology and its management and this was collected from the hospital files, Postoperative morbidities that included wound infection, general surgical complications, intra-peritoneal collection, postoperative hospital stay, postoperative pain (the need for analgesia), the needed time to return to work and tubal adhesions and this was collected through postoperative visits within 3 months.

\section{Statistical Analysis:-}

All patients' data were collected, checked and analyzed by using (SPSS version 20). Data were expressed as mean \pm standard deviation (SD) and number with (\%) according to type of variable. Chi-square test $\left(\chi^{2)}\right.$ or Fischer's exact t test or Mann-Whitney were used when appropriate. $\mathrm{P}$ value $<0.05$ was considered statistically significant.

\section{Results:-}

The total included patients in the present study were 54. 27 patients underwent OA and 27 patients under-went LA, was followed up for three months in this study. The OA and LA groups participants' mean age was $27.41 \pm 7.35$ and $26.04 \pm$ 7.02 respectively $(\mathrm{P}=0.471)$.

The average skin to skin operation time was $25.89 \pm 12.89 \mathrm{~min}$ in $\mathrm{OA}$ hand and $63.7 \pm 13.83$ in LA hand $(\mathrm{P}<0.001)$ which was highly selective difference (Figure 1). Patients' mean hospital stay was $1.70 \pm 0.95$ days for patients in OA group while this period was $1.15 \pm 0.36$ days for LA group $(\mathrm{P}=0.026)$ (Figure 2$)$. According to visits of follow up, $\mathrm{OA}$ group of patients have resumed their normal daily activities after $9 \pm 1.94$ days, while period for OA patients was $3.74 \pm$ 0.65 days and this was highly significant statistical diference $(\mathrm{P}<0.001)$ (Figure 3$)$.

Post-operative complication rate was higher in OA group, wound infection $(n=18)$ in OA group while ( $n=3)$ in LA group, Ileus $(n=10)$ in OA group while $(n=5)$ in LA group, chest infection $(n=2)$ and DVT $(n=1)$ in OA group with no morbidity cases in LA group (table 1).

Post-operative pain was measured by VAS (Visual Analogue Scale) on first postoperative day found to be mild ( $\mathrm{n}=16$ ) in OA group and $(n=24)$ in LA group, moderate was $(n=6)$ in OA group and $(n=2)$ in LA group and severe was $(n=5)$ in OA group and $(n=1)$ in LA group (table 1), (Figure 4).

About number of days of analgesia using was $(4.89 \pm 0.84)$ days in OA while $(2.07 \pm 0.26)$ days in LA $(\mathrm{P}<0.001)$ which was highly selective difference (table 2).

Through follow up visits after 3 months of operation we did HSG of both groups we found that there were tubal adhesions $(n=17)$ in OA group and $(n=4)$ in LA group $(\mathrm{P}<0.001)$ which was highly selective difference (Figure 5).

Table 1:- Open appendectomy versus Laparoscopic appendectomy as regard postoperative complications.

\begin{tabular}{|c|c|c|c|c|c|c|}
\hline \multirow[t]{2}{*}{$\begin{array}{l}\text { Postoperative } \\
\text { complications }\end{array}$} & \multicolumn{2}{|c|}{$\begin{array}{l}\text { Open appendectomy } \\
(\mathrm{N}=27)\end{array}$} & \multicolumn{2}{|c|}{$\begin{array}{l}\text { Laparoscopic } \\
\text { appendectomy }(\mathrm{N}=27)\end{array}$} & \multirow[t]{2}{*}{ Test $^{\S}$} & \multirow[t]{2}{*}{$\begin{array}{l}\text { p-value } \\
\text { (Sig.) }\end{array}$} \\
\hline & No & $\%$ & No & $\%$ & & \\
\hline \multicolumn{7}{|l|}{ Pain } \\
\hline Mild & 16 & $59.3 \%$ & 24 & $88.9 \%$ & \multirow[t]{3}{*}{6.267} & \multirow[t]{3}{*}{$0.044(\mathrm{~S})$} \\
\hline Moderate & 6 & $22.2 \%$ & 2 & $7.4 \%$ & & \\
\hline Severe & 5 & $18.5 \%$ & 1 & $3.7 \%$ & & \\
\hline Wound infection & 18 & $66.7 \%$ & 3 & $11.1 \%$ & 17.532 & $<0.001(\mathrm{HS})$ \\
\hline Ileus & 10 & $37 \%$ & 5 & $18.5 \%$ & 2.308 & $0.129(\mathrm{NS})$ \\
\hline Pneumonia & 2 & $7.4 \%$ & 0 & $0 \%$ & 2.077 & $0.150(\mathrm{NS})$ \\
\hline DVT & 1 & $3.7 \%$ & 0 & $0 \%$ & 1.019 & $0.313(\mathrm{NS})$ \\
\hline
\end{tabular}


Table 2:- Open appendectomy vs Laparoscopic appendectomy as regard post-operative analgesia.

\begin{tabular}{|l|l|l|l|l|}
\hline Postoperative analgesia & $\begin{array}{l}\text { Open appendectomy } \\
\text { (N=27) }\end{array}$ & $\begin{array}{l}\text { Laparoscopic } \\
\text { appendectomy } \\
\text { (N=27) }\end{array}$ & Test & $\begin{array}{l}\text { p-value } \\
\text { (Sig.) }\end{array}$ \\
\hline Number of days of analgesia use & & & & \\
\hline Mean \pm SD & $4.89 \pm 0.84$ & $2.07 \pm 0.26$ & $-6.728 \bullet$ & $\begin{array}{l}<0.001 \\
(\mathrm{HS})\end{array}$ \\
\hline Median (Range) & $5(3-7)$ & $2(2-3)$ & & \\
\hline
\end{tabular}

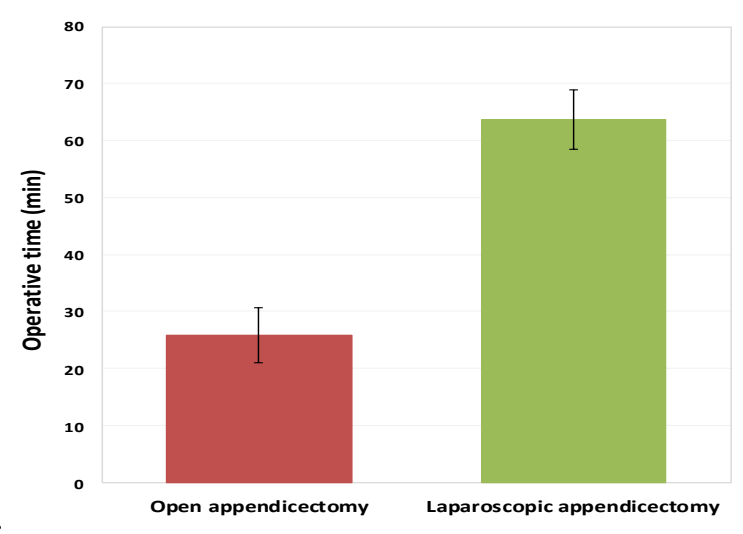

Figure 1:- Error Bar chart shows comparison between Open appendectomy and Laparoscopic appendectomy as regard operative time ( $\mathrm{min})$; bar represent mean, Y-error bar represent $95 \%$ confidence interval of mean.

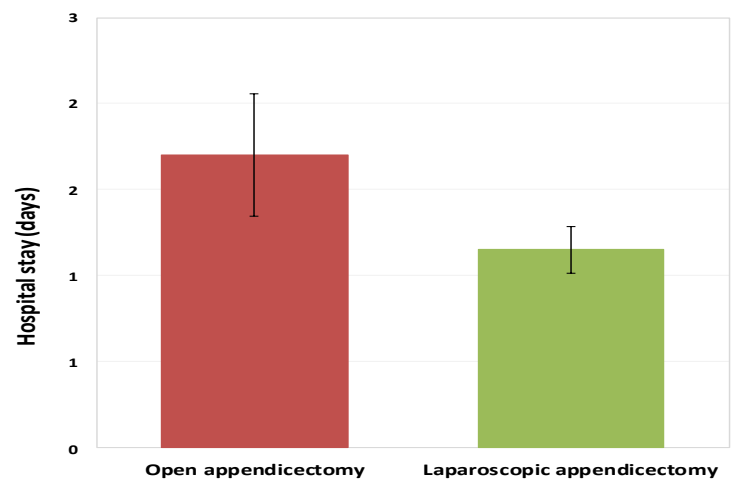

Figure 2:- Error Bar chart shows comparison between Open appendectomy and Laparoscopic appendectomy as regard hospital stay (days); bar represent mean, Y-error bar represent 95\% confidence interval of mean.

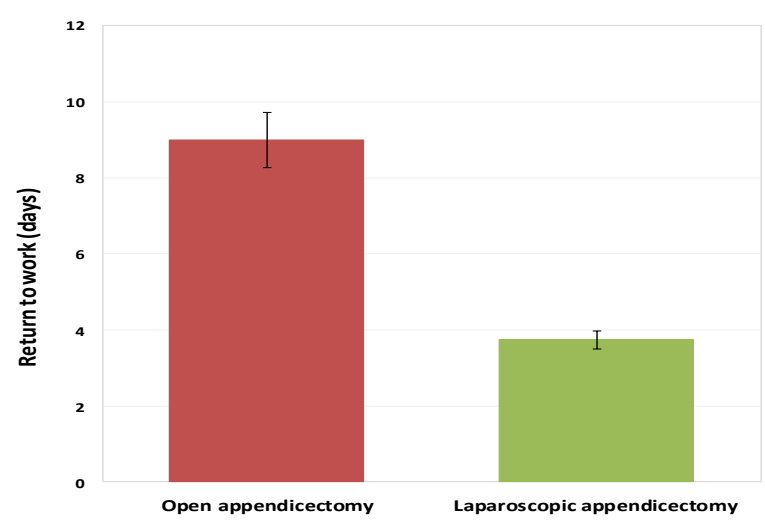

Figure 3:-Error Bar chart shows comparison between Open appendectomy and Laparoscopic appendectomy as regard return to work (days); bar represent mean, Y-error bar represent 95\% confidence interval of mean. 


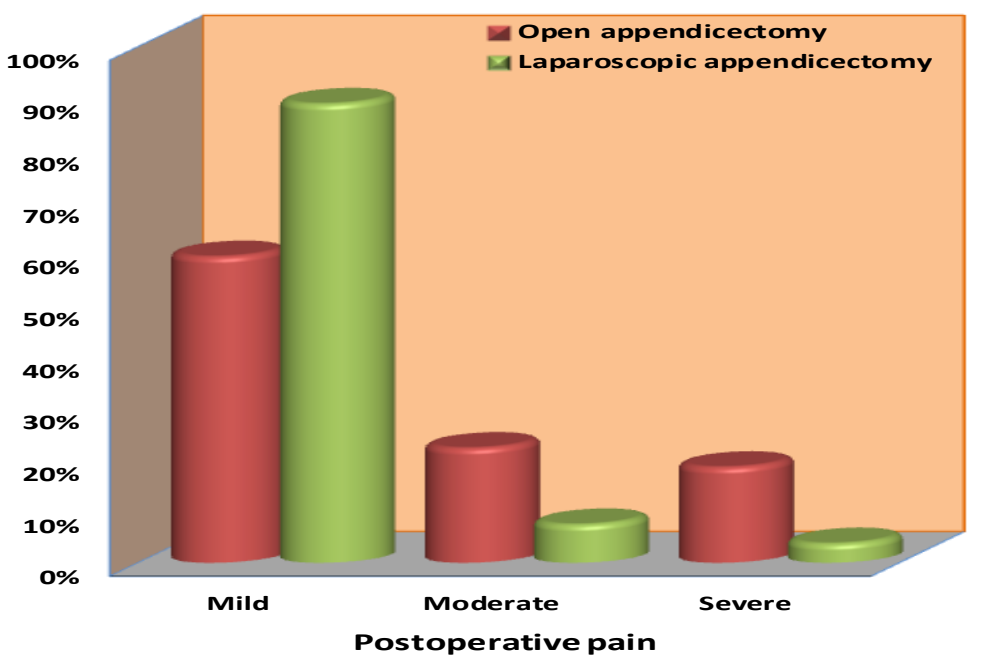

Figure 4:- Bar chart shows comparison between Open appendectomy and Laparoscopic appendectomy as regard postoperative pain.

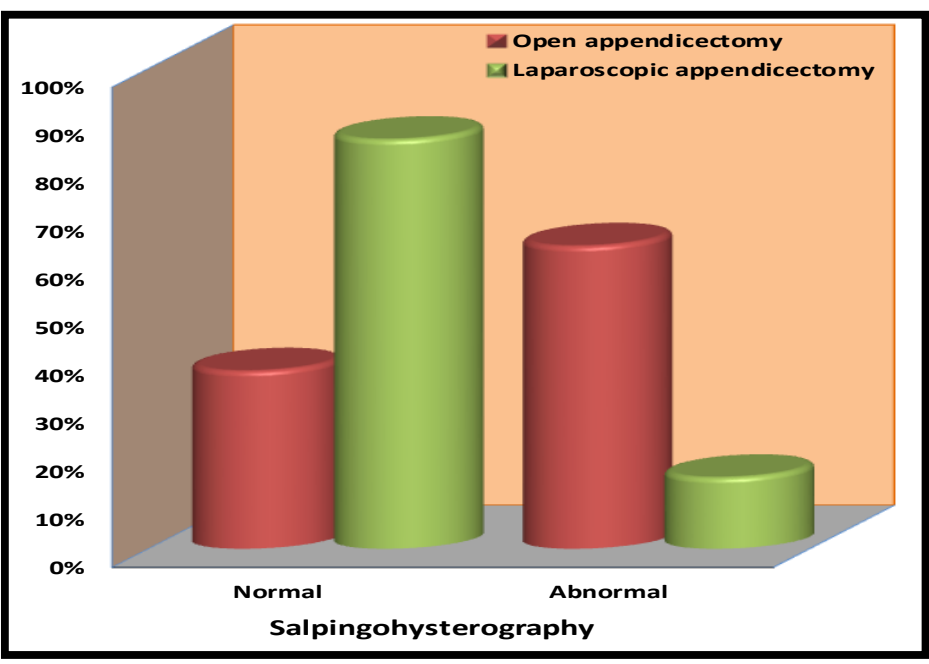

Figure 5:- Bar chart shows comparison between Open appendectomy and Laparoscopic appendectomy as regard hysterosalpingography.

\section{Discussion:-}

Regarding using laparoscopy as a significant approach for surgical management of appendicitis, it is still a matter of controversy whether such approach is feasible and safer than the open approach.

LA procedure assessment involved consideration of plethora of factors as previously mentioned. Our purpose in the current study was to compare between LA and OA as regard time of the operation, intra-operative and postoperative outcomes about three months postoperatively in women in the childbearing period. The current study showed that there were highly significant differences between both included groups regarding time of operation $(\mathrm{p}<0.001)$. Similarly, several studies showed a shorter time of operation in the OA approch ${ }^{(5)}$, while others didn't show any significant differences ${ }^{(6)}$ and some reported a shorter operation time for LA (Figure 1) ${ }^{(7)}$.

In our study showed that there was shorter hospital stay in LA with mean time $(1.15 \pm 0.36)$ compared to OA $(1.70 \pm$ 0.95). Our results are nearly similar to those of Guller and his collogues in (2004), where the length of hospital stay was significantly shorter after laparoscopic appendectomy with mean time (2.6) days while (3.8) days in open appendectomy (Figure 2) ${ }^{(8)}$. 
In this study there was a high significant difference between both groups about return cases to normal activity with mean time was $(9 \pm 1.94)$ days in OA and $(3.74 \pm 0.65)$ days in LA. Our finding is in agreement with a similar study by Hellberg and his collogues in (1999), that demonstrates median time to full recovery as 13 days in LA and 21 days in the OA (P < 0.0001) and other randomized clinical trials and meta-analysis, Pedersen et al., (2001) for cost effectiveness of LA, the hospital cost for LA was higher, but it offers significant cost savings from the rapid convalescence. Return to normal life and work was faster in LA. The hospital costs of LA were higher but the total costs were lower (Figure 3) ${ }^{(9,10)}$.

In terms of postoperative outcome, significant difference was noted between the two groups, postoperative pain was measured by VAS ( Visual Analogue Scale) on first postoperative day found to be mild in $16(59.3 \%)$ in OA and in 24 $(88.9 \%)$ in LA, moderate was $6(22.2 \%)$ in OA and in $2(7.4 \%)$ in LA and severe was $5(18.5 \%)$ in OA and in $1(3.7 \%)$ in LA although all patients in both groups took postoperative analgesics as our protocol in our emergency department according to severity of pain either ,NSAID only in $16(59.3 \%)$ in OA and $24(88.9 \%)$ in LA, or combination of two types of analgesic drugs in $11(40.7 \%)$ in OA and $3(11.1 \%)$ in LA and about number of days of analgesia using was (4.89 \pm $0.84)$ days in $\mathrm{OA}$ while $(2.07 \pm 0.26)$ days in LA. Our findings were similar to results demonstrated by other previous studies that stated the requirement of less analgesic due to less pain in LA (table 1,2$)^{(10,11)}$.

Wound infections might not be considered a serious complication but it represented a major discomfort to the patients which negatively affecting her quality of life. In our study, 18 patients (66.7\%) in OA and only 3 cases (11.1\%) in LA had wound/port infections or some sort of wound dehiscence. Wound infections were more common in the OA. The majority of studies have concluded that wound infections were significantly lower after laparoscopic appendectomy ${ }^{(8,12,13)}$. Furthermore, laparoscopic surgery is associated with better preservation of the immune system than open surgery. (Table 1) ${ }^{(14)}$.

Postoperative ileus in our study was twice in OA than in LA, 10 patients (37\%) in OA while only 5 patients (18.5\%) in LA. This is agreed with a study done by Katkhouda and his collogues in (2005), which reported that laparoscopic surgery reduces postoperative ileus with early switch to oral diet (table 1) ${ }^{(4)}$.

In this study reported that there were 2 cases $(7.4 \%)$ of pneumonia and one case $(3.7 \%)$ of DVT in OA with no morbidity cases in LA. This is agreed with a study done Tiwari and his collogues in (2011) that stated low morbidity complications of laparoscopic appendectomy in comparison with open appendectomy (table 1) ${ }^{(15)}$.

In this study we aim to detect any fallopian tube adhesions in our cases and which is better for decreasing that either OA or LA ,so we did HSG one day after doing OA and doing tubal patency evaluation intra-operatively for LA to exclude any previous tubal adhesions then after 3 months we did HSG for both groups, we found that there were tubal adhesions in 17 cases $(63 \%)$ in OA and only 4 cases $(14.8 \%)$ in LA, stating that LA had low incidence of pelvic adhesions postoperatively in comparison with OA.

This is in line with previous studies which have reported the rate of adhesion occurrence which reached $80 \%$ after OA while it was only $10 \%$ after LA. The reason or reduction in the adhesion rate formation, which is considered a long term advantage of LA is due to less tissue trauma of the incision in LA than OA which decreasing the inflammatory response, increasing fibrinolysis, inhibiting migration of fibroblasts and decreasing collagen formation (Figure 5) ${ }^{(16-19)}$.

\section{Conclusions:-}

Based on this study, we conclude that:

Although the operative time of LA is still longer that OA but LA is a safe and feasible surgical approach of management of appendicitis. LA has many benefits over OA as it has less incidence of post-operative wound infection, shorter duration of hospital stay, less post-operative pain that subsequently reduced the need for post- operative analgesics use and rabid return to normal daily activities. Additionally LA helps in diagnose the patients' case accurately specially in equivocal cases in women during their childbearing period.

Laparoscopy could be routinely used for all young females' patients who presented with pain in the right iliac fossa. Conclusions of the present study were supported by results of many recent studies that LA was more beneficial than OA. 


\section{Recommendations:-}

we would like to recommend further trials comparing LA and OA not only for short-term outcomes, but also for long-term outcomes up to 10 years. Further study needs to be undertaken to clearly demonstrate the long-term outcomes of both procedures. Secondly, where the facilities and expertise is available for LA, the choice for treating acute appendicitis with laparoscopic procedure can be safely decided by the patient and the operating surgeon.

\section{References:-}

1. Moberg A, Berndsen F and Palmquist I (2005): "Randomized clinical trial of laparoscopic versus open appendectomy for confirmed appendicitis "Br J Surg., 92: 298-304.

2. Lin H, Wu J and Tseng L (2006): "Laparoscopic versus open appendectomy for perforated appendicitis" J Gastro-intest surg., 10: 906-10.

3. Ignacio R, Burke R and Spencer D (2004): "Laparoscopic versus open appendectomy: what is the real difference? Results of a prospective randomized double-blinded trial "Surg Endosc., 18:334-7.

4. Katkhouda N, Rodney J., Shirin T and Rahila E (2005): "Laparoscopic Versus Open Appendectomy: a Prospective Randomized Double-Blind Study " Ann Surg., 242(3): 439-450.

5. Meroao A (1999): "Laparoscopic Versus Open Appendectomy J KAU" Med. Sci., Vol. 7 No.1, pp. 85-91.

6. Kehagias I, Karamanakos S and Kalfarentzos F (2008): " Laparoscopic versus open appendectomy: which way to go?" World J Gastroenterol., 14: 4909-1.

7. Heikkinen T, Haukipuro K and Hulkko A (1998): " Cost-effective appendectomy. Open or Laparoscopic? A prospective randomized study" Surg Endosc ., 12(10): 1204-8.

8. Guller U, Hervey S and Purves H (2004): " Laparoscopic versus open appendectomy: outcomes comparison based on a large administrative database" Ann Surg., 239:43-52.

9. Hellberg A, Rudberg C, Kullman E, Enochsson L, Fenyö G and Graffner H (1999): "Prospective randomized multiCentre study of laparoscopic versus open appendectomy" Br J Surg., 86;48-53.

10. Pedersen A, Petersen $O$ and Wara O (2001): "Randomized clinical trial of Laparoscopic versus open appendicectomy" Br J Sur., 88:200-205.

11. Ortega A, Hunter J, Peters J, Swanstrom L and Schirmer B (1995): "Prospective randomized comparison of laparoscopic appendectomy with open appendectomy "Am J Surg., 169: 208-13.

12. Kamal M and Qureshi K (2003): "Laparoscopic versus open appendectomy" Department of Surgery, Nishtar Medical College, Multan. Pakistan. J. Med. Res., Vol. 42 No.1.

13. Sauerland S, Jaschinski T and Neugebauer E (2010): "Laparoscopic versus open surgery for suspected appendicitis" Cochrane Database of Systematic Reviews Published by JohnWiley \& Sons, Ltd., 93-96.

14. Targarona E, Knook C, Balague M and Trias M (2000): "Laparoscopic surgery and surgical Infection "Br J Surg., 87: 536-544.

15. Tiwari M, Reynoso $\mathbf{J}$ and Tsang A (2011): "Comparison of outcomes of laparoscopic and open appendectomy in management of uncomplicated and complicated appendicitis" Ann Surg., 254: 927-932.

16. Ashraf A and Khaled M (2013): "Laparoscopic appendectomy in complicated appendicitis: is it safe?" J Minim Access Surg., 9(2):55-58.

17. Wei B, Qi C and Chen T (2011): "Laparoscopic versus open appendectomy for acute appendicitis: a metaanalysis" Surg Endosc.,25(4):1199-208.

18. Garrrard C, Clements R and Nanney L (1999): "Adhesion formation is reduced after laparoscopic surgery" Surg Endosc., 13:10-13.

19. Cuschieri A (1997): "Appendectomy- Laparoscopic or open" Surg Endosc. 11:319-320. 